Manuelle Medizin 2018 $\cdot 56: 480$ https://doi.org/10.1007/s00337-0180476-4

(c) Springer Medizin Verlag $\mathrm{GmbH}$, ein Teil von Springer Nature 2018

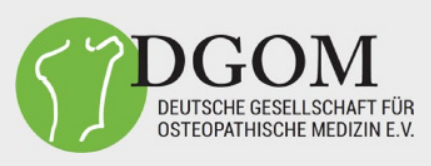
DEUTSCHE GESELLSCHAFT FÜR
OSTEOPATHISCHE MEDIZIN E.V.

\section{Deutsche Gesellschaft} für Osteopathische Medizin (DGOM) e.V.

Goethestraße 18
68161 Mannheim
Tel.: 0621/4362 6692
Fax: 0621/4362 6691
Internet: kontakt@dgom.info
www.dgom.info

V.i.S.d.P.

Dr. med. Ute Beckmann Berliner Str. 40 63654 Büdingen

\title{
Kursprogramm 2019 (Auszug)
}

\section{Nähere Informationen und das gesamte \\ Kursprogramm finden Sie unter www.dgom.info}

\section{Grundcurriculum}

\section{GKOM/T}

30.03.-31.03.19

01.06. -02.06 .19$

21.09. -22.09 .19$

23.11. -24.11 .19$

\section{MET 1}

29.03.-31.03.19

27.09. -29.09 .19$

\section{MET 2}

10.05.-12.05.19

18.10.-20.10.19

\section{MET 3}

12.04.-14.04.19

11.10.-13.10.19

\section{MFR 1}

30.08.-01.09.19

22.09. -24.09 .19$

\section{MFR 2}

28.06.-30.06.19

29.11.-01.12.19

Boppard

Mannheim

Anatomie (Schwangere können nicht teilnehmen)

21.06.-23.06.19

20.09.-22.09.19

Düsseldorf

Düsseldorf

Pariet. Integr.

05.04.-07.04.19

25.10.-27.10.19

Mannheim

Boppard (OV)

\section{Cranio 2}

03.05.-05.05.19

15.11.-17.11.19

Mannheim

Mainz

Cranio 3

15.03.-17.03.19

25.10.-27.10.19

Mannheim

Lübeck

VIS 1

08.03.-10.03.19 Berlin

27.09.-29.09.19 Mannheim

VIS 2

10.05.-12.05.19 Mannheim

22.11.-24.11.19 Mainz

VIS 3

28.06.-30.06.19 Mannheim

29.11.-01.12.19 Boppard

CoSt

23.08.-25.08.19 Mannheim

\section{Func 1}

14.06.-16.06.19 Mannheim 06.12.-08.12.19 Berlin

\section{Func 2}

22.03.-24.03.19 Mannheim

06.09.-08.09.19 Boppard

Schon seit vielen Jahren bietet die DGOM in Zusammenarbeit mit der DGMSM ein integriertes Curriculum zum Erlernen der manuellen und osteopathischen Techniken in einem abgestimmten, flexiblen Zeitrahmen an.

Jeder Arzt und jeder Physiotherapeut, der bei der DGOM in die Osteopathieausbildung startet, kann das Curriculum bis zum Abschluss durchlaufen.

\section{Sie haben noch Fragen?}

www.dgom.info

oder rufen Sie uns an: 0621-4362 6692

\section{Cranio 1}

06.09.-08.09.19

Mannheim 